\title{
Precision medicine in Parkinson's disease: emerging treatments for genetic Parkinson's disease
}

\author{
Susanne A. Schneider ${ }^{1} \cdot$ Roy N. Alcalay ${ }^{2}$ \\ Received: 23 October 2019 / Revised: 8 January 2020 / Accepted: 10 January 2020 / Published online: 23 January 2020 \\ (c) The Author(s) 2020
}

\begin{abstract}
In recent years, numerous clinical trials for disease modification in Parkinson's disease (PD) have failed, possibly because of a "one-size-fits all" approach. Alternatively, a precision medicine approach, which customises treatments based on patients' individual genotype, may help reach disease modification. Here, we review clinical trials that target genetic forms of PD, i.e., $G B A$-associated and $L R R K 2$-associated PD. In summary, six ongoing studies which explicitely recruit $G B A$-PD patients, and two studies which recruit $L R R K 2-\mathrm{PD}$ patients, were identified. Available data on mechanisms of action, study design, and challenges of therapeutic trials are discussed.
\end{abstract}

Keywords Genetic Parkinson's disease · SNCA · GBA · LRRK2 - Kinase inhibitor · Small molecule compounds · Venglustat $\cdot$ Ambroxol $\cdot$ Clinical trial $\cdot$ TORC1 inhibitor $\cdot$ Superprecision medicine

Parkinson's disease (PD) is the second most common neurodegenerative disorder, affecting more than 6 million people worldwide [1]. Numerous drugs for the treatment of PD are avilable on the market. While drugs targeting the dopaminergic pathway treat motor symptoms, there is no evidence that they modify disease progression. This "one-size-fits all" approach may very well explain why clinical trials for disease modification in PD have failed. Treatments that target the underlying pathophysiology are required. Since the pathophysiology of PD may be different in different patients, studies should be designed that assess PD treatment on a more individual basis. Therefore, a precision medicine approach in PD is very timely.

Susanne A. Schneider and Roy N. Alcalay equally contributed to writing of the first draft and to review and critique.

Susanne A. Schneider

susanne.schneider@med.uni-muenchen.de

1 Department of Neurology, Ludwig-Maximilians-University of München, Marchioninistr. 15, 81377 Munich, Germany

2 Department of Neurology, Columbia University Medical Center, New York, NY, USA

\section{Precision medicine-a conceptual framework}

Precision medicine-also referred to as personalized medicine or individualized medicine-aims to tailor the specific treatment for the right person at the right time. To achieve this, it uses diagnostic tools to identify specific biomarkers, often genetic, to help assess which medical treatments will be best for each patient [2]. By combining data from these tests with a patient's medical history and important factors influencing health status, targeted prevention and treatment plans can hopefully be developed in the future [2]. Thus, precision medicine is not a new concept. It is a conceptual framework which became a hot topic beyond the medical sphere when President Obama announced a research initiative that aims to accelerate progress toward a new era of precision medicine in 2015 [3]. There are various benefits of precision medicine, including the detection of disease onset at the earliest moment and thereby shifting the emphasis in medicine from reaction to prevention (Table 1).

In the context of neurodegenerative disorders, at the time of clinical manifestation (and certainly at the time of diagnosis), a substantial number of neuros has been permanently lost. Hence, early detection of at-risk individuals will be instrumental for early treatments (which will ideally protect the cells from neuronal death). Sucessful precision medicine will thus move from current reactive 
approaches to early detection, protection and prevention. Early detection of individuals at-risk to develop neurodegenerative disorders is a major challenge. However, in the case of genetic subforms, early detection is feasible by confirming their genetic status with a minimal-invasive test.

\section{The genetic architecture of Parkinson's disease}

In the past decade, we have seen incredible progress in elucidating the genetic architecture of PD: over a dozen Mendelian loci are known to cause familial PD. In addition, multiple loci have been identified by genome-wide association studies (GWAS) that are mostly associated with a small increase in risk of PD. These latter genetic variations of weak effect strength may occur as commonly as $40 \%$ in the general population, but convey only a mildly (up to $~ 1.5$-fold) increased disease risk [4]. Even when combining all risk factors, the odds ratio is only 3-4 (i.e. there is a 3 to 4 times increased risk of developing the disease) [5]. Notably, alteration in the same gene may lead to different variants and mutations with differrent risk association with PD [6]. For example, some point mutations in $L R R K 2$ are causative for PD, while coding polymorphisms in the gene are strong risk factors and additional higher frequency variants at the $L R R K 2$ locus contribute to a small increase in risk of developing PD [7].

A recent meta-analysis suggested that the detectible heritable component of PD (based on genome-wide SNPs and less significant SNPs included in a polygenic risk score) is around $20 \%$ [8]. There is compelling evidence of yet-to-be-discovered additional genetic factors that contribute to the etiology of PD. In addition, environmental risk factors are yet to be discovered.

This tremendous progress in understanding the genetic architecture has set the ground for the development of treatments based on disease mechanism rather than symptoms. Here, we will review clinical trials which target genetic forms of PD, i.e., explicitly recruit (or enrich for) patients with a genetic form of PD.

\section{Parkinsonism associated with GBA mutations}

Homozygous mutations in the glucocerebrosidase $(G B A)$ gene cause Gaucher disease (GD), the most common autosomal recessive lysosomal storage disease, with an estimated annual incidence of 1/60,000 and an estimated carrier frequency [9] of $0.7-0.8 \%$ in the general population. Some ethnicities show higher mutation rates; specifically, in the Ashkenazi Jewish (AJ) population, there is an annual incidence is 1/1,000 and carrier frequencies as high as $6 \%$ in all $\mathrm{AJ}$.

The clinical presentation of GD can be divided into systemic, which are present in all forms of GD, and include hepatosplenomegaly, painful skeletal disorders and pancytopenia, and neurological manifestations, which are present in the more severe types of GD, GD-II and GD-III. Both GD patients and healthy heterozygous carriers are at increased risk for PD [10] and longterm follow-up showed worsening in motor and non-motor prodromal PD features [11]. $G B A$ mutations are a common risk for $\mathrm{PD}$ and are present in $7-10 \%$ of PD patients worldwide. Among Ashkenazi Jews, around $20 \%$ of PD patients carry a GBA mutation [12]. High prevalences have also been reported in the Netherlands, where $15 \%$ of PD patients carry a $G B A$ mutation (oral communication, Dana Hilt). The lowest carrier frequency was reported to be $2.3 \%$ in Norwegian Parkinson's disease patients [13]. Notably, there is considerable reduction of penetrance in that only about $10 \%$ of GBA carriers will develop PD (which is however considerably higher compared to the global PD prevalence of $1-2 \%$ of the general population aged 65 years or older) and studies suggest that penetrance is age-dependent [14].

Clinically, $G B A$ heterozygotes may be indistinguishable from iPD. However, they may have an earlier age at onset, more prevalent cognitive impairment and may not respond to levodopa as well as iPD patients $[15,16]$. GBA mutations are also associated with other alpha-synucleinopathies, including DLB [17] (pathologically confirmed) and in some, but not all studies, with MSA [18-22]. In contrast, there was no association with essential tremor or AD (Alzheimer's disease).

More than 300 mutations in GBA have been reported [23], some with milder (e.g., the N370S mutation), others with
Table 1 Benefits of precision medicine [2]

\footnotetext{
Diagnose disease more accurately

Select optimal therapies and target medicines and dosages precisely

Increase safety, reduce adverse drug reactions

Detect onset of disease at the earliest moment, incl. detection of early subclinical correlates of neuronal death prior to clinical (motor) manifestation

Shift emphasis in medicine from reaction to prevention (i.e., protection of neurons to avoid neuroal death) Increase the efficiency of the health system by improving quality
} 
more severe (e.g., the L444P mutation) biological consequences and clinical presentations (e.g., age at onset or progression rate). The encoded protein, glucocerebrosidase, is a lysosomal enzyme which plays a role in the breakdown of glucocerebroside into glucose and ceramide. In GD, there is lysosomal build-up of the substrate glucocerebroside in the reticulo-endothelial system with reduced clearance capacities.

Pathologically, the brains of patients with heterozygous $G B A$ mutations strongly resemble those from patients with iPD. However, there is also widespread cortical Lewy body involvement in $G B A$ mutation carriers [16, 22]. A few studies showed a reciprocal relationship between levels of glucocerebrosidase (Gcase; the enzyme encoded by $G B A$ ) and levels of the aggregate-prone protein alpha-synuclein [24]. Notably, iPD patients also have reduced GCase activity (about 33\% decrease) in the substantia nigra and cerebellum, making treatments that target $G B A$ relevant for iPD and patients with PD dementia as well [21].

While the PD field can benefit from decades of research done for GD, the underlying mechanisms of how exactly
$G B A$ leads to the development of PD are not fully understood. One of the hypotheses is that there is a self-propagating bidirectional feedback loop between GCase and a-synuclein. On the one hand, loss of GCase activity causes a-synuclein accumulation and oligomerization, resulting in neurotoxicity through aggregate-dependent mechanisms [25]. Furthermore, elevated a-synuclein inhibits lysosomal maturation and normal GCase activity. a-synuclein hinders GCase transport from the endoplasmic reticulum to the lysosome. This continues over time until the threshold for neurodegeneration is reached [25].

Based on this, targeted treatments can take different approaches including modulation of gylcosphingolipid turnover and restoration of enzyme function (Table 2; Fig. 1).

\section{Treatment directed at modulation of gylcosphingolipid turnover}

Substrate reduction therapy inihibits the biosynthesis of lipid subtrates and thereby prevents their accumulation. While this

Table 2 GBA-targeting treatments for PD in the clinical phase aiming at modulation of glycosphingolipid turnover and restoration of enzyme function

\begin{tabular}{|c|c|c|c|c|c|c|}
\hline \multirow{2}{*}{$\begin{array}{l}\text { GBA } \\
\text { Compound }\end{array}$} & $\begin{array}{l}\text { MOVES-PD study } \\
\text { Part } 1\end{array}$ & \multirow{2}{*}{$\begin{array}{l}\text { MOVES-PD study } \\
\text { Part } 2\end{array}$} & \multicolumn{4}{|l|}{ AiM-PD } \\
\hline & Venglustat (GZ/SAR402671) & & Ambroxol & RTB101 & LTI-291 & PR001 \\
\hline Administration & \multicolumn{2}{|l|}{ Oral } & Oral & Oral & Oral & Injections \\
\hline Sponsor & \multicolumn{2}{|l|}{ Sanofi } & $\begin{array}{l}\text { UCL and Cure PD } \\
\text { Trust }\end{array}$ & Restorbio & LTI/Allergan & Prevail \\
\hline RCT No & \multicolumn{2}{|l|}{ NCT02906020 } & \multicolumn{2}{|l|}{ NCT02941822 } & \multicolumn{2}{|l|}{$\begin{array}{l}\text { (NL7061; }^{\text {NTR7299) }} \\
\text { NTR }\end{array}$} \\
\hline Mechanism & \multicolumn{2}{|c|}{$\begin{array}{l}\text { Glucosylceramide synthase inhibiton; } \\
\text { reduction of GBA-related GSLs }\end{array}$} & GCase activation & TORC1 inhibition & GCase activation & $\begin{array}{l}\text { Gene therapy, AAV- } \\
\text { based }\end{array}$ \\
\hline Status & Completed & $\begin{array}{l}\text { Recruiting, } \\
\text { estimated primary } \\
\text { completion } 2021\end{array}$ & $\begin{array}{l}\text { Estimated comple- } \\
\text { tion } 04-2018\end{array}$ & $\begin{array}{l}\text { Ongoing; data } \\
\text { expected } 2020\end{array}$ & $\begin{array}{l}\text { Recruiting in } \\
\text { Leiden (NL) }\end{array}$ & $\begin{array}{l}\text { Clinical centers } \\
\text { initiated }\end{array}$ \\
\hline Phase & 2 & & $2 \mathrm{a}$ & $1 \mathrm{~b} / 2 \mathrm{a}$ & $1 b$ & $1 b$ \\
\hline Design & $\begin{array}{l}\text { Multicenter, } \\
\text { randomized, } \\
\text { double-blind, } \\
\text { placebo-con- } \\
\text { trolled, sequen- } \\
\text { tial cohort }\end{array}$ & $\begin{array}{l}\text { Prospective, single- } \\
\text { centre, open label }\end{array}$ & $\begin{array}{l}\text { Multicenter 2:1 } \\
\text { randomized } \\
\text { double-blind, } \\
\text { placebo-con- } \\
\text { trolled }\end{array}$ & $\begin{array}{l}\text { Multicenter, 2:1 } \\
\text { randomized, } \\
\text { double-blind, } \\
\text { placebo-con- } \\
\text { trolled }\end{array}$ & $\begin{array}{l}\text { Randomized, pla- } \\
\text { cebo-controlled, } \\
\text { double-blind, } \\
\text { parallel study }\end{array}$ & $\begin{array}{l}\text { Randomized, dou- } \\
\text { ble-blind, sham } \\
\text { procedure-con- } \\
\text { trolled, ascending } \\
\text { dose study }\end{array}$ \\
\hline Total $N$ of part & 17 & & $10+10$ & 45 & Apprx. 40 & $30 / 16$ \\
\hline GBA-PD & $\sqrt{ }$ & & $\sqrt{ }$ & $\sqrt{ }$ & $\sqrt{ }$ & $\sqrt{ }$ \\
\hline Idiopathic PD & No & & $\sqrt{ }$ & $\sqrt{ }$ & No & $\sqrt{ }$ \\
\hline Age & $\begin{array}{l}18-80 \text { yrs (mean } \\
58 \text { yrs) }\end{array}$ & & $40-80$ yrs & & 18 years or older & \\
\hline Duration & 36 weeks & $\begin{array}{l}52 \text { weeks }+104 \text { weeks } \\
\text { extension }\end{array}$ & 6 months & 4 weeks & 28 days & \\
\hline Doses tested & 3 escalating doses & 1 dose & 5 escalating doses & $\begin{array}{l}300 \mathrm{mg} ; \pm \text { siroli- } \\
\text { mus }\end{array}$ & $\begin{array}{l}10 \text { or } 60 \mathrm{mg} \text { once } \\
\text { daily }\end{array}$ & $\begin{array}{l}\text { Two escalating dose } \\
\text { cohorts }\end{array}$ \\
\hline
\end{tabular}

${ }^{a}$ see https://www.trialregister.nl/trial/7061 for more information 


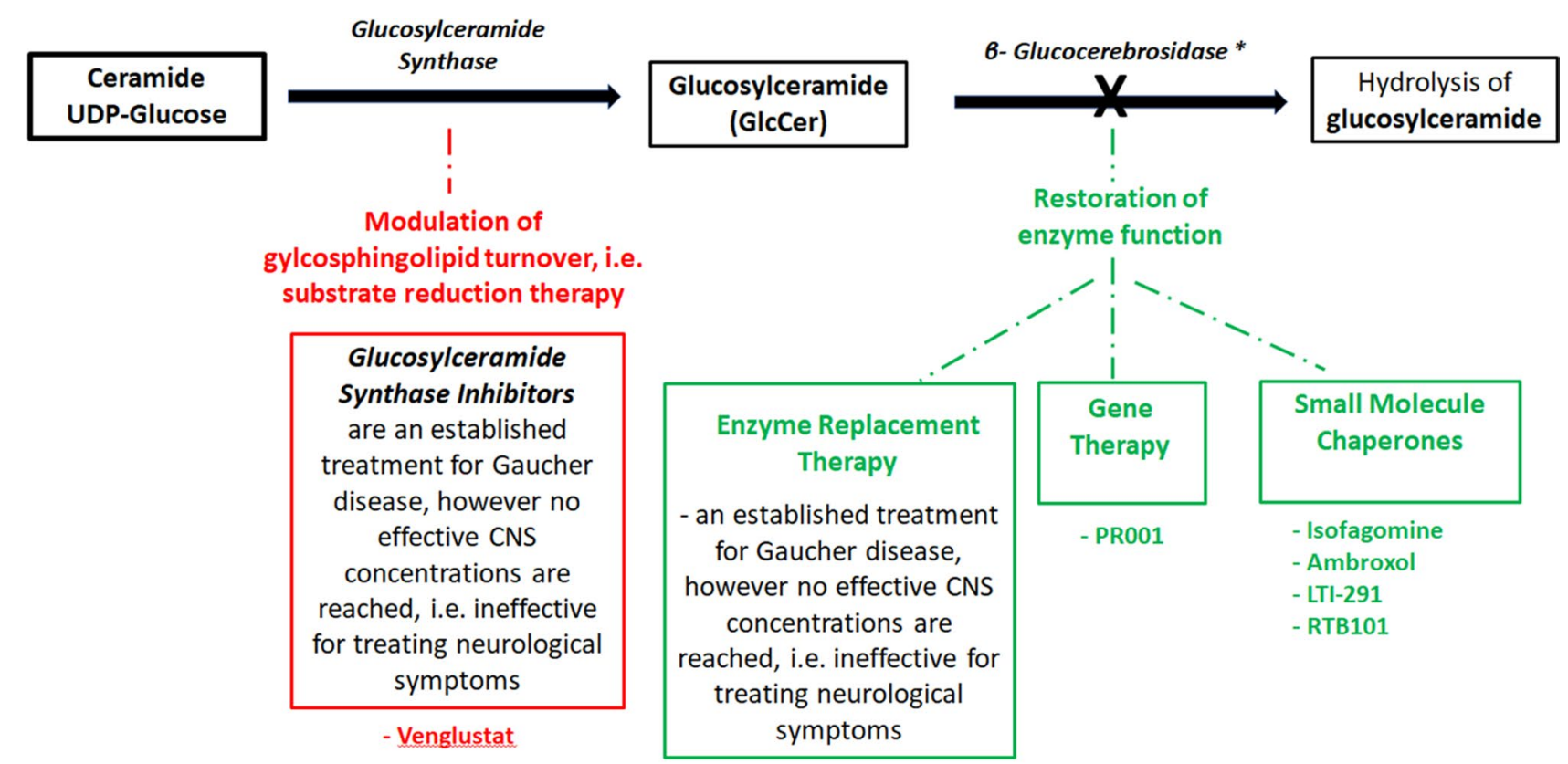

* Enzyme deficiency in GBA leads to build-up of GlcCer

Fig. 1 Treatment approaches for GBA-associated PD include modulation of gylcosphingolipid turnover and restoration of enzyme function

approach does not target the mutant gene or dysfunctional enzyme itself, it is an effective FDA approved treatment of the systemic symptoms of Gaucher disease. However, the approved inhibitors show no effective CNS concentration and do not affect the neurological symptoms of Gaucher disease (i.e., Gaucher type II and III). However, new glucosylceramide synthase inhibitors, show good brain penetration and improved a-synuclein processing and behavioural outcomes in mouse models [26, 27]. Based on these findings, Sanofi launched the MOVES-PD study, a randomized, double-blind, placebo-controlled trial, to assess the efficacy and safety of the glycosylsynthase inhibitor Venglustat (GZ/SAR402671). Initial results from a phase I study were recently published [28]. Briefly, 17 GBA-PD were enrolled (13 on venglustat, 4 on placebo; mean age 58 years, mean disease duration 7 years) into this 36 -week randomized placebo-controlled double-blind sequential cohort study of once daily venglustat at three escalating doses. No serious adverse events occurred. Side effects included psychological, neurological and gastrointestinal-related symptoms. Plasma and cerebrospinal fluid (CSF) glucosylceramide levels decreased in a dose-dependent manner (up to 75\%). This favorable safety and tolerability profile of venglustat at all doses led the company to advance to a phase II, a 52-week trial which is currently ongoing [28].

\section{Treatment directed at restoration of enzyme function}

Other therapies focus on restoration of enzyme function, thus increasing glucocerebrosidase activity, especially in the brain. This can be achieved by (1) enzyme-replacement therapy (ERT) with recombinant glucocerebrosidase. This treatment is available for patients with Gaucher disease. However, as in the case of the currently approved substrate reduction therapies, ERT does not cross the blood-brain barrier and does cannot affect the neurological symptoms found in GD Type II and III. Of note, there are no data on the use of ERT in PD.

Another approach would be (2) gene therapy using adenoassociated virus vectors to deliver engineered DNA to human cells [27, 29]. As for $G B A$, preclinical studies in mice demonstrated that adeno-associated virus-mediated expression of glucocerebrosidase corrected the aberrant accumulation of the toxic lipid glucosylsphingosine and reduced the levels of ubiquitin, tau, and alpha-synuclein aggregates [30]. Prevail Therapeutics, a new company launched in 2017, aims to start clinical trials with PR001 in 16 GBA-PD patients in late 2019 [31]. The company will also test the compound in children with neuropathic Gaucher disease starting in the first half of 2020.

Furthermore, (3) small molecules have attracted attention [32]. Early glucocerebrosidase chaperones that underwent clinical trials for Gaucher disease included isofagomine (afegostat-tartrate, AT2101). This treatment did not lead to 
significant clinical improvement, and further clinical development for this indication was discontinued [27].

Ambroxol, which is a promising small molecule chaperone widely used in Europe as a mucolytic agent, may potentially facilitate the transit of the misfolded GCase protein to the lysosome [33]. Ambroxol has been shown to improve lysosomal function and increase enzyme activity in in-vitro studies utilizing dermal fibroblasts with GBAl mutations [34] as well as in studies performed on non-human primates (i.e., cynomolgus monkeys) with GBAl mutations [35]. The effects of ambroxol at high doses are currently being studied in the AiM-PD study, sponsored by UCL and the Cure Parkinson's Trust, UK [36]. Twenty PD patients (10 GBA-positive \& 10 GBA-negative status) are treated with up to $420 \mathrm{mg} /$ day (which is considerably higher compared to $30-120 \mathrm{mg}$ used for the treatment of respiratory disease) in order to evaluate the safety, tolerability and pharmacodynamics of ambroxol at five escalating doses. Outcome measures include clinical assessments of motor and cognitive function as well as blood and CSF biomarkers. As mentioned above, GCase activity is also reduced in iPD patients' brains (SN) [37], making the therapy potentially relevant for iPD. The effect of ambroxol in non-GBA-PD [36] and non-GBA-PD dementia [38] will be better understood once results from the two ongoing studies become available which include ten non-GBA-PD and 75 PDD patients $[38,39]$ (treated at a daily doses of $420 \mathrm{mg} /$ day or $525-1050 \mathrm{mg}$ / day, respectively).

The effects of the activator of the GCase enzyme LTI291 were studied in a one-month phase $1 \mathrm{~b}$ trial conducted in the Netherlands, where the rate of $G B A$ mutations are reported to be around 15\%. Around 40 GBA-PD patients participated. There were no safety events and data showed a good dose-dependent brain penetration (personal communication). The company, Lysosomal Therapeutics, Inc. (LTI), is a Massachusetts-based biotech venture, which plans to develop therapies for Gaucher disease and other lysosomebased neurodegenerative diseases.

Small molecules have also targeted PD by modifying $G B A$-independent pathways. One such example is RTB101, which is an inhibitor of target of rapamycin complex 1 (TORC1) [40]. Rapamycin, which is known for its immunosuppressant properties, prolongs lifespan by $15-25 \%$ in various non-mammalian organisms, even when given late in life; it has also been found to increase health-span. A five year-study in dogs is planned to test geroprotective effects of RTB101 in mammals [41]. Rapamycin reached public attention when Bloomberg magazine publicized it as the potential "forever pill" on its cover in 2015, which reflects the great desire of rejuvenation. TORC1 plays a role in cell growth, aging and is the switch between fasting and feeding states [40]. Mutations in TORC1 cause focal cortical dysplasia, an established cause of epilepsy. The role of mTORC1 in regulating autophagy may also have implications for neurodegenerative diseases. In preclinical models, TORC1 inhibition induces autophagy and prevents neuronal loss [41, 42]. It improves motor function in multiple PD models including a-synuclein transgenic mice and MPTP models of PD [43]. In oncology cell cultures, treatment with RTB101 reduced the levels of glucosylceramide, the main substrate of GCase. A current phase $1 \mathrm{~b} / 2 \mathrm{a}$ trial of RTB101 in combination with sirolimus involved 45 PD patients with or without $G B A$ mutation. The study was initiated in early 2019 ; data are expected in 2020 .

\section{LRRK2-associated Parkinsonism: kinase inhibitors are a promosing target}

LRRK2 mutations are the most common cause of autosomal dominant PD accounting for $5-15 \%$ of dominant familial PD and $1-3 \%$ of sporadic PD (Fig. 2). The International LRRK2 Consortium study estimated that the most common mutation in $L R R K 2, \mathrm{G} 2019 \mathrm{~S}$, alone accounts for $1 \%$ of sporadic and $4 \%$ of familial PD patients [44].

Similar to $G B A$, mutations in LRRK2 are more common in certain ethnicities. North African Arabs (mutation-positive: $36 \%$ in familial, $39 \%$ in sporadic PD) and Ashkenazi Jews (28\% in familial, $10 \%$ in sporadic PD) have the highest frequencies. As in $G B A$, different mutations and variants confer different levels of risk for PD. For example, the G2019S mutation, which is common in Whites, confers a higher risk for PD than the common Asian variants, G2385R and R1628P $[11,13]$. These latter two variants are detected in around 5-10\% of Asian PD patients [45]. The G2385R variant is associated with an odds ratio of 2.24. Penetrance in LRRK2 is age-dependent and estimations in the general population are widely variable, ranging between 30 and $74 \%$ $[46,47]$.

Additionally, non-coding polymorphisms close to the $L R R K 2$ locus act as risk factors for sporadic disease [48] Furthermore, $L R R K 2$ interacts with the protein products of at least two GWAS hits, RAB7L1 and GAK, linking PDrelated genes with monogenic and complex forms $[49,50]$.

$L R R K 2$ is a large gene with 51 exons, spanning a genomic region of $144 \mathrm{~kb}$. It contains five functional domains including a leucine rich repeat domain. More than 80 missense mutations have been reported, but only around one dozen are pathogenic [48]. The mechanisms by which mutations cause PD have not been completely disentangled yet, but there is increasing evidence of increased LRRK2 kinase function in PD. The G2019S mutation, for example, results in a direct two-to-threefold increase in kinase activity [51, 52]. Others studies have focused on the GTP domain which may also play an important role. Loss of function, on the other hand, 
Fig. 2 World map of LRRK2associated Parkinsonism. 533 cases have been reported. Circles reflect frequency per region. Data and image were retrieved from the MDSGene Website [47]

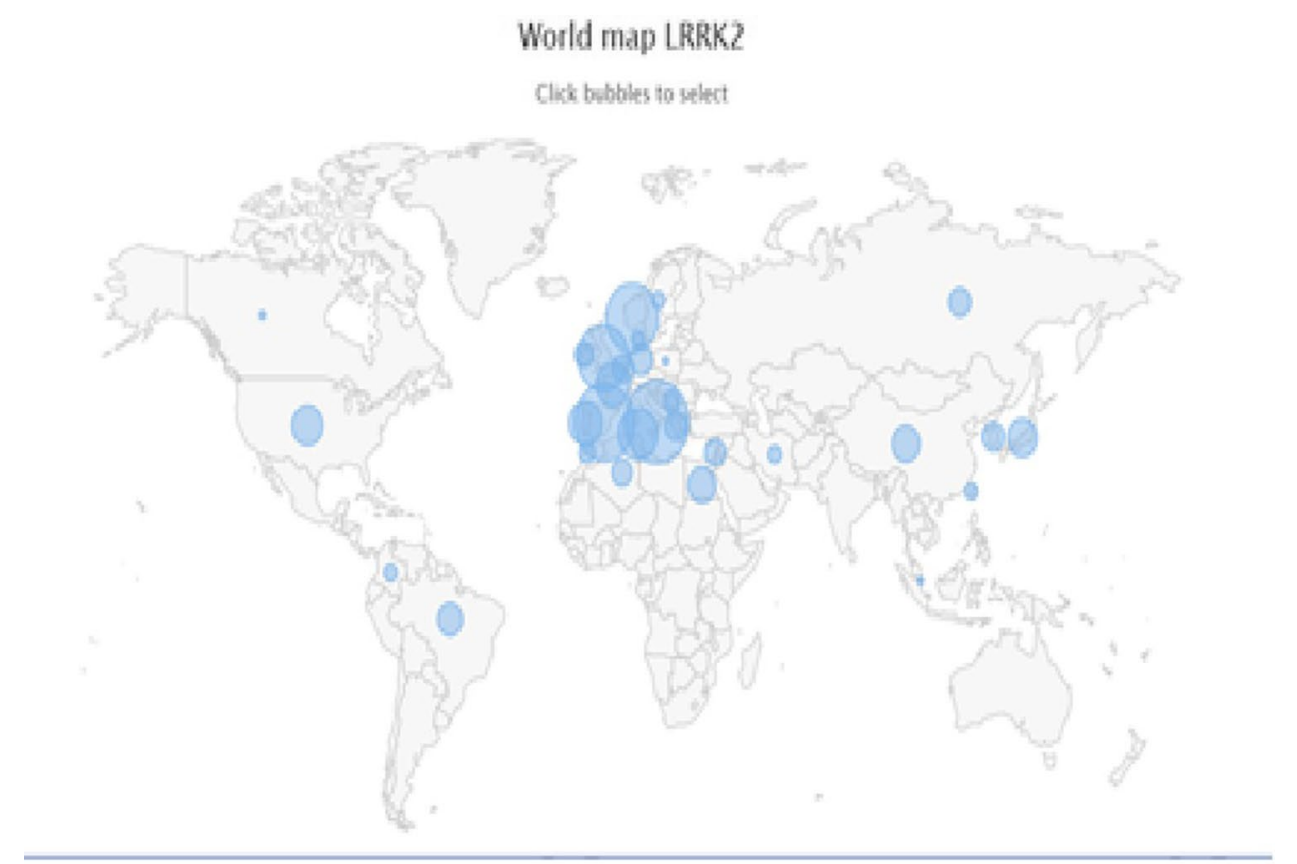

i.e., by haploinsufficiency of LRRK1 or LRRK2, appears to be neither a cause of nor protective against PD [53].

The potential gain-of-function effect would be an attractive target for treatment because inhibition is easier to achieve than improvement of reduced protein activity (as in $G B A$ ). Furthermore, kinase inhibitors are widely used in oncology, and the PD field can benefit from such achievements in other fields. Since the first generation of LRRK2 inhibitors, newer compounds have progressively improved in potency, selectivity, and brain penetrance. However, efficacy and safety remain a concern. That is because other tissues, particularly the kidney, lung, and a subtype of peripheral immune cells, robustly express LRRK2. For example, the kidney has a $\sim 6.2$-fold higher expression of LRRK2 compared to the brain [52]. This is a potential source of peripheral side effects, which can include abnormal accumulations, a-syn aggregations, and impaired autophagy-lysosomal function induced by LRRK2 inhibitors [53-55]. More recent data, however, suggest that compounds that only partially downregulate LRRK2 levels or kinase activity, i.e., by $50 \%$ or less, are unlikely to produce major side effects related to on-target safety [56] and lipid droplets in lamelar bodies are absored after the drug is withdrawn. One alternative to avoid systemic toxicity is to find a way to specifically modify LRRK2 activity in the brain without modifying activity peripherally. Several strucutrally different LRRK2 inhibitors from Genentech, GSK, Merck and Pfizer are in the pipeline (Table 3) [27]. The compound developed by Denali is already in clinical trial. A phase $1 \mathrm{~b}$ trial in healthy individuals has been completed, which included pulmonary and renal safety parameters. The company is advancing DNL201
(GNE-7915) to a Phase 1b safety and biomarker study in LRRK2-linked PD and iPD. 30 mild to moderately affected PD patients with or without LRRK2 mutation will be randomized to low or high dose DNL201 or placebo in this 28-day randomized placebo-controlled trial. The first patient was reported in December 2018; data readout is expected for the end of 2019. To facilitate recruitment, a "directto-consumer" approach for testing and counselling will be available [57]-a strategy that proved successful in genetic testing with the PPMI initiative. Most recently, Denali has announced a strategic collaboration with a gene diagnostic lab, Centogene, in order to globally identify and recruit LRRK2 mutation carriers, further characterize this genetic subtype, and build a source for patient recruitment for future studies [58]. However, such strategies of a commercial diagnostic lab in concert with a drug company to offer directed to consumer diagnostic testing is viewed critically by some.

Finally, Biogen is currently recruiting LRRK2 patients into one arm of a phase 1 trial. These patients will receive a single intrathecal injection of the compound BIIB094, an antisense oligomere (ASO), on multiple days. Recently, ASOs have produced a lot of interst in a variety of disorders, including spinal muscular atrophy, Huntington's disease or non-neurological disorders such as cancers [59, 60]. ASOs reduce the expression of a mutated gene by binding to target mRNAs and blocking the translation of the abnormal protein or inducing its degradation [60]. ASOs can also promote splicing around mutations. For disorders due to toxic gainof-function such as LRRK2, further investigation regarding ASOs is warranted. In a preclinical study, administration of LRRK2 ASOs to the brains of mice reduced LRRK2 protein 
Table 3 LRRK2-targeted treatments including LRRK2 inihibitors and antisense oligomeres under development for PD

\begin{tabular}{|c|c|c|c|c|c|}
\hline LRRK2 & Denali trial & & & & \\
\hline Compound & DNL-201 & No public data & No public data & No public data & BIIB094 \\
\hline Sponsor & Denali & GSK & Pfizer & Genetech & Biogen \\
\hline RCT No & NCT03710707 & & & & NCT03976349 \\
\hline Mechanism & LRRK2 inhibition & LRRK2 inhibition & LRRK2 inhibition & LRRK2 inhibition & Antisense oligomere \\
\hline Status & $\begin{array}{l}\text { Ongoing, recruiting, } \\
\text { data expected end of } \\
2019\end{array}$ & Planned & Under development & Under development & Ongoing \\
\hline Phase & $1 \mathrm{~b}$ & $\mathrm{~N} / \mathrm{a}$ & N/a & N/a & Phase 1 \\
\hline Design & $\begin{array}{l}\text { Multicenter, rand- } \\
\text { omized, placebo- } \\
\text { controlled }\end{array}$ & N/a & N/a & N/a & \\
\hline Total $N$ of pat & 30 & N/a & N/a & N/a & 62 \\
\hline LRRK2-PD & $\sqrt{ }$ & N/a & N/a & N/a & $\sqrt{ }$ \\
\hline Idiopathic PD & $\sqrt{ }$ & N/a & N/a & N/a & $\sqrt{ }$ \\
\hline Age & $30-75$ & $\mathrm{~N} / \mathrm{a}$ & $\mathrm{N} / \mathrm{a}$ & N/a & $35-80$ \\
\hline Duration & 28 days & N/a & N/a & N/a & N.d. \\
\hline Doses tested & Low / High & N/a & N/a & N/a & $\begin{array}{l}\text { Single-and multiple- } \\
\text { ascending-dose }\end{array}$ \\
\hline
\end{tabular}

levels and fibril-induced $\alpha$-syn inclusions [61]; data from humans are not yet available.

Interestingly, most recent studies found an mechanistic and therapeutic convergence of LRRK2 and GCase with reduced GCase activity in dopaminergic neurons derived from PD patients with LRRK2 mutations and increased GCase activity induced by inhibition of LRRK2 kinase activity [62]. Rab10 was identified as a key mediator of LRRK2 regulation of GCase activity and may be an interesting target for future studies [62].

\section{Final remarks}

Recent failures in large Phase III clinical trials for PD suggest that disease modification would be difficult to achieve as long as we treat PD as one disease one pathophysiology. Therefore, we believe that precision medicine in PD may be a promising alternative.

As summarized in this review, several gene-targeted therapies are being tested in clinical trials and numerous more are in the pipeline. These are exciting times. However, the process of bringing a drug into the clinic is cumbersome [63]. Pharmaceutical Research and Manufacturers of America (PhRMA) estaimate that for every 5000-10,000 compounds screened, only 250 enter preclinical testing, five enter human clinical trials, and one is approved by the Food and Drug Administration, with only two in ten drugs generating enough revenue to recoup their research and development costs [64]. Thus, set-backs will not come unexpected.
In addition to the hurdles of all clinical trials, precision medicine trials may be more complicated. It is unclear who may benefit from precision medicine drugs. Would these be useful only for mutation carriers (and therefore require an orphan drug assignment) or would they be beneficial for the larger group of idiopathic PD or atypical parkinsonian disorders? It seems unlikely that all these patients will respond to the same drug. Indeed, even within the group of $G B A$ mutation carriers, one may have to differentiate due to the effect that a specific mutation has on the protein. For example, the affinity of chaperones to a mutated enzyme may be different depending on the mutation. Furthermore, a new drug that facilitates protein function may fail in patients with null mutations who do not express any protein. The term "superprecision medicine" has been used to capture this phenomenon.

There are challenges that remain that need to be overcome when planning or conducting a clinical trial (Table 4) [65]. A major challenge will be to recruit a large enough number of study participants. Genotyping significantly larger proportions of PD patients would be required. Different strategies have been developed for this purpose, including the Parkinson's Foundation effort called PD GENE and the "direct-to-consumer" approach, which may allow identification of eligible individuals even if they do not live close to a movement disorders unit. Raising awareness and educating the community, including physicians, patients and caregivers, will be an important step to reach critical numbers. We are hopeful that the treatment for PD will drastically change in the next decade and evolve beyond dopaminergic or surgical treatments. 
Table 4 Top four challenges and barriers to effective clinical trials as perceived by health professionals, patients, and their caregivers-for full list see [65]

\begin{tabular}{ll}
\hline Scientists and other health professionals & Patients and caregivers \\
\hline Lack of funding & Risk of potential adverse consequences and potential side effects \\
Lack of administrative support and time available to manage the trial & Disruption to normal medication regimen \\
Slow and difficult recruitment of people & Prospect of receiving a placebo instead of the active drug \\
Lack of practical support & Upheaval and inconvenience to life that trial participation would cause \\
\hline
\end{tabular}

Another challenge is the relative lack of biomarkers that reliably reflect disease progression and response to treatment. This applies to genetic subtypes as well as the larger group of iPD in general. Concerted efforts are being made to identify a biospecimen-based (i.e., blood, urine, CSF or biopsy), imaging, or other (e.g., electrophyiological) biomarker of PD or disease progression. Among these, the PPMI initiative is a valuable source that brings together longitudinal data and specimen collection from more than 1200 volunteers with PD [66].

Advancing precision medicine will further encourage and support the next generation of scientists to develop creative new approaches for detecting, measuring, and analyzing a wide range of biomedical information-including molecular, genomic, cellular, clinical, behavioral, physiological, and environmental parameters [3].

Acknowledgements Open Access funding provided by Projekt DEAL. We thank Baccara Hizli for assistance with data collection and Mr. Joshua Halpern for his careful work editing the manuscript.

Funding S. Schneider was supported by LMU Clinician Scientist Programme, the Ara Parseghian Medical Research Fund, and the Verum Stiftung. She received a publication honorium from Springer Publishers.

\section{Compliance with ethical standards}

Conflicts of interest Dr. Alcalay reports receiving consultation fees from Genzyme/Sanofi, Roche and ResTORbio.

Open Access This article is licensed under a Creative Commons Attribution 4.0 International License, which permits use, sharing, adaptation, distribution and reproduction in any medium or format, as long as you give appropriate credit to the original author(s) and the source, provide a link to the Creative Commons licence, and indicate if changes were made. The images or other third party material in this article are included in the article's Creative Commons licence, unless indicated otherwise in a credit line to the material. If material is not included in the article's Creative Commons licence and your intended use is not permitted by statutory regulation or exceeds the permitted use, you will need to obtain permission directly from the copyright holder. To view a copy of this licence, visit http://creativecommons.org/licenses/by/4.0/.

\section{References}

1. Dorsey ER, Elbaz A, Nichols E, Abd-Allah F, Abdelalim A, Adsuar JC et al (2018) Global, regional, and national burden of Parkinson's disease, a systematic analysis for the global burden of disease study. Lancet Neurol 17:939-953

2. Abrahams E, President I personalized medicine coalition personalized medicine: The changing landscape of health care; key note lecture, The 2 nd biomarker meeting in personalized reproductive medicine valencia, Spain [http://www.comtecmed.com/ biomarker/2014/Uploads/Editor/PDF/ppt/Edward\%20Abrahams _Key\%20Note\%20Lecture.pdf]. Accessed 16 Jan 2020

3. Collins FS, Varmus H (2015) A new initiative on precision medicine. N Engl J Med 372:793-795

4. Gasser T (2015) Usefulness of genetic testing in PD and PD trials: a balanced review. J Park Dis 5:209-215

5. Nalls MA, Pankratz N, Lill CM et al (2014) Large-scale metaanalysis of genome-wide association data identifies six new risk loci for Parkinson's disease. Nat Genet 46:989-993

6. van der Brug MP, Singleton A, Gasser T, Lewis PA (2015) Parkinson's disease: from human genetics to clinical trials. Sci Transl Med 7:205ps220

7. Paisan-Ruiz C, Lewis PA, Singleton AB (2013) LRRK2: cause, risk, and mechanism. J Parkinsons Dis 3:85-103

8. Nalls MA, Blauwendraat C, Vallerga CL et al (2019) Identification of novel risk loci, causal insights, and heritable risk for Parkinson's disease: a meta-analysis of genome-wide association studies. Lancet Neurol 18:1091-1102

9. Zuckerman S, Lahad A, Shmueli A et al (2007) Carrier screening for Gaucher disease: lessons for low-penetrance, treatable diseases. JAMA 298:1281-1290

10. Sidransky E, Nalls MA, Aasly JO et al (2009) Multicenter analysis of glucocerebrosidase mutations in Parkinson's disease. N Engl J Med 361:1651-1661

11. Mullin S, Beavan M, Bestwick J et al (2019) Evolution and clustering of prodromal parkinsonian features in GBA1 carriers. Mov Disord 34:1365-1373

12. Gan-Or Z, Giladi N, Rozovski U et al (2008) Genotype-phenotype correlations between GBA mutations and Parkinson disease risk and onset. Neurology 70:2277-2283

13. Toft M, Pielsticker L, Ross OA, Aasly JO, Farrer MJ (2006) Glucocerebrosidase gene mutations and Parkinson disease in the Norwegian population. Neurology 66:415-417

14. Rana HQ, Balwani M, Bier L, Alcalay RN (2013) Age-specific Parkinson disease risk in GBA mutation carriers: information for genetic counseling. Genet Med 15:146-149

15. Clark LN, Ross BM, Wang Y et al (2007) Mutations in the glucocerebrosidase gene are associated with early-onset Parkinson disease. Neurology 69:1270-1277

16. Clark LN, Kartsaklis LA, Wolf Gilbert R et al (2009) Association of glucocerebrosidase mutations with dementia with lewy bodies. Arch Neurol 66:578-583 
17. Geiger JT, Ding J, Crain B et al (2016) Next-generation sequencing reveals substantial genetic contribution to dementia with Lewy bodies. Neurobiol Dis 94:55-62

18. Mitsui J, Matsukawa T, Sasaki H et al (2015) Variants associated with Gaucher disease in multiple system atrophy. Ann Clin Transl Neurol 2:417-426

19. Sklerov M, Kang UJ, Liong C, Marder K, Pauciulo M, Nichols WC, Chung WK, Honig LS, Cortes E, Vonsattel JP (2017) Frequency of GBA variants in autopsy-proven multiple system atrophy. Mov Disord Clin Pract 4(4):574-581

20. Segarane B, Li A, Paudel R et al (2009) Glucocerebrosidase mutations in 108 neuropathologically confirmed cases of multiple system atrophy. Neurology 72:1185-1186

21. Nishioka K, Ross OA, Vilarino-Guell C et al (2011) Glucocerebrosidase mutations in diffuse Lewy body disease. Parkinsonism Relat Disord 17:55-57

22. Goker-Alpan O, Giasson BI, Eblan MJ et al (2006) Glucocerebrosidase mutations are an important risk factor for Lewy body disorders. Neurology 67:908-910

23. Hruska KS, LaMarca ME, Scott CR, Sidransky E (2008) Gaucher disease: mutation and polymorphism spectrum in the glucocerebrosidase gene (GBA). Hum Mutat 29:567-583

24. Mazzulli JR, Xu YH, Sun Y et al (2011) Gaucher disease glucocerebrosidase and alpha-synuclein form a bidirectional pathogenic loop in synucleinopathies. Cell 146:37-52

25. Barkhuizen M, Anderson DG, Grobler AF (2016) Advances in GBA-associated Parkinson's disease-Pathology, presentation and therapies. Neurochem Int 93:6-25

26. Sardi SP, Viel C, Clarke J et al (2017) Glucosylceramide synthase inhibition alleviates aberrations in synucleinopathy models. Proc Natl Acad Sci USA 114:2699-2704

27. Sardi SP, Cedarbaum JM, Brundin P (2018) Targeted Therapies for Parkinson's Disease: From Genetics to the Clinic. Mov Dis 33:684-696

28. Peterschmitt M, Gasser T, Isaacson S et al (2019) Safety, tolerability and pharmacokinetics of oral venglustat in Parkinson disease patients with a GBA mutation. Mol Genet Metabol Rep 126:S117

29. Hitti FL, Yang AI, Gonzalez-Alegre P, Baltuch GH (2019) Human gene therapy approaches for the treatment of Parkinson's disease: an overview of current and completed clinical trials. Parkinsonism Relat Dis 66:16-24

30. Sardi SP, Clarke J, Viel C et al (2013) Augmenting CNS glucocerebrosidase activity as a therapeutic strategy for parkinsonism and other Gaucher-related synucleinopathies. Proc Natl Acad Sci USA 110:3537-3542

31. Prevail therapeutics: Prevail is developing a pipeline of potentially disease-modifying AAV9-based gene therapies for the treatment of genetically-defined neurodegenerative diseases: PR001. By: Prevail therapeutics. https://www.prevailtherapeu tics.com/programs/\#pr001

32. McMahon B, Aflaki E, Sidransky E (2016) Chaperoning glucocerebrosidase: a therapeutic strategy for both Gaucher disease and Parkinsonism. Neural Regen Res 11:1760-1761

33. Maegawa GH, Tropak MB, Buttner JD et al (2009) Identification and characterization of ambroxol as an enzyme enhancement agent for Gaucher disease. J Biol Chem 284:23502-23516

34. McNeill A, Magalhaes J, Shen C et al (2014) Ambroxol improves lysosomal biochemistry in glucocerebrosidase mutation-linked Parkinson disease cells. Brain 137:1481-1495

35. Migdalska-Richards A, Ko WKD, Li Q, Bezard E, Schapira AHV (2017) Oral ambroxol increases brain glucocerebrosidase activity in a nonhuman primate. Synapse. https://doi. org/10.1002/syn.21967
36. Trust hcginNsbSUaCPs. identification number: NCT02914366; sponsored by Sponsor: Lawson Health Research Institute. https ://clinicaltrials.gov

37. Gegg ME, Burke D, Heales SJ et al (2012) Glucocerebrosidase deficiency in substantia nigra of parkinson disease brains. Ann Neurol 72:455-463

38. Silveira CRA, MacKinley J, Coleman K et al (2019) Ambroxol as a novel disease-modifying treatment for Parkinson's disease dementia: protocol for a single-centre, randomized, doubleblind, placebo-controlled trial. BMC Neurol 19:20

39. Institute hoginNsbSLHR. Available

40. Saxton RA, Sabatini DM (2017) mTOR signaling in growth, metabolism, and disease. Cell 169:361-371

41. Savage N (2017) New tricks from old dogs join the fight against ageing. Nature 552:S57-S59

42. Spilman P, Podlutskaya N, Hart MJ et al (2010) Inhibition of mTOR by rapamycin abolishes cognitive deficits and reduces amyloid-beta levels in a mouse model of Alzheimer's disease. PLoS ONE 5:e9979

43. Decressac M, Bjorklund A (2013) mTOR inhibition alleviates L-DOPA-induced dyskinesia in parkinsonian rats. J Parkinsons Dis 3:13-17

44. Healy DG, Falchi M, O'Sullivan SS et al (2008) Phenotype, genotype, and worldwide genetic penetrance of LRRK2-associated Parkinson's disease: a case-control study. Lancet Neurol 7:583-590

45. Lim SY, Tan AH, Ahmad-Annuar A et al (2019) Parkinson's disease in the Western Pacific Region. Lancet Neurol 18(9):865-879

46. Ozelius LJ, Senthil G, Saunders-Pullman R et al (2006) LRRK2 G2019S as a cause of Parkinson's disease in Ashkenazi Jews. N Engl J Med 354:424-425

47. MDS Gene (2019) PARK-LRRK2 data summary. International parkinson and movement disorder society. University of Lübeck. Retrieved on April 18, 2019. https://www.mdsgene.org/d/1/ $\mathrm{g} / 1$ ?action $=$ plot_map $\& \mathrm{fc}=0 \& \_\mathrm{mu}=1 \&$ \&country $=1$

48. West AB (2015) Ten years and counting: moving leucine-rich repeat kinase 2 inhibitors to the clinic. Mov Dis 30:180-189

49. MacLeod DA, Rhinn H, Kuwahara T et al (2013) RAB7L1 interacts with LRRK2 to modify intraneuronal protein sorting and Parkinson's disease risk. Neuron 77:425-439

50. Manzoni C, Denny P, Lovering RC, Lewis PA (2015) Computational analysis of the LRRK2 interactome. PeerJ 3:e778

51. Jaleel M, Nichols RJ, Deak M et al (2007) LRRK2 phosphorylates moesin at threonine-558: characterization of how Parkinson's disease mutants affect kinase activity. Biochem J 405:307-317

52. Atashrazm F, Dzamko N (2016) LRRK2 inhibitors and their potential in the treatment of Parkinson's disease: current perspectives. Clin Pharmacol 8:177-189

53. Blauwendraat C, Reed X, Kia DA et al (2018) Frequency of loss of function variants in LRRK2 in Parkinson disease. JAMA Neurol 75:1416-1422

54. Fuji RN, Flagella M, Baca M et al (2015) Effect of selective LRRK2 kinase inhibition on nonhuman primate lung. Sci Transl Med 7:273ra215

55. Baptista MAS, Merchant K, Barrett T, Bryce DK, Ellis M, Estrada AA et al (2018) LRRK2 kinase inhibitors induce a reversible effect in the lungs of non-human primates with no measurable pulmonary deficits. BioRxiv. https://doi. org/10.1101/390815v1

56. Whiffin N, Armean IA, Kleinman A, Marshall JL, Minikel EV, Goodrich JK et al (2019) Human loss-of-function variants suggest that partial LRRK2 inhibition is a safe therapeutic strategy for Parkinson's disease. BioRxiv. https://doi.org/10.1101/56147 $2 \mathrm{v} 2$ 
57. Foroud T, Smith D, Jackson J et al (2015) Novel recruitment strategy to enrich for LRRK2 mutation carriers. Mol Genet Genomic Med 3:404-412

58. Centogene AG (2018): Centogene and denali therapeutics announce strategic collaboration to recruit LRRK2 patients for clinical trials. Hg. v. Centogene AG. https://www.centogene. com/company/article/centogene-and-denali-therapeutics-annou nce-strategic-collaboration-to-recruit-lrrk2-patients-for-cli.html

59. Coutinho MF, Matos L, Santos JI, Alves S (2019) RNA therapeutics: how far have we gone? Adv Exp Med Biol 1157:133-177

60. Platt FM, d'Azzo A, Davidson BL, Neufeld EF, Tifft CJ (2018) Lysosomal storage diseases. Nat Rev Dis Primers 4:27

61. Zhao HT, John N, Delic V et al (2017) LRRK2 Antisense oligonucleotides ameliorate alpha-synuclein inclusion formation in a parkinson's disease mouse model. Mol Ther Nucleic Acids 8:508-519

62. Ysselstein D, Nguyen M, Young TJ et al (2019) LRRK2 kinase activity regulates lysosomal glucocerebrosidase in neurons derived from Parkinson's disease patients. Nat Commun 10:5570

63. Analysis Group, Inc (2017) The biopharmaceutical pipeline: innovative therapies in clinical development. Unter mitarbeit von genia long. Analysis Group, Inc.https://www.analysisgroup. com/uploadedfiles/content/insights/publishing/the_biopharmac eutical_pipeline_report_2017.pdf

64. The Pharmaceutical Research and Manufacturers of America (PhRMA) (2009) PHarmaceutical Research and Manufacturers of America (PhRMA) SPECIAL 301 SUBMISSION 2009. http://phrmadocs.phrma.org/sites/default/files/pdf/phrma_speci al_301_submission_20092.pdf

65. Mathur S, DeWitte S, Robledo I, Isaacs T, Stamford J (2015) Rising to the challenges of clinical trial improvement in Parkinson's disease. J Parkinsons Dis 5:263-268

66. Marek K, Chowdhury S, Siderowf A et al (2018) The Parkinson's progression markers initiative (PPMI)-establishing a PD biomarker cohort. Ann Clin Transl Neurol 5:1460-1477 